\title{
Qualidade de pele e produtividade da cultivar de batata BRS Clara
}

\author{
Giovani O da Silva ${ }^{1}$; Arione da S Pereira ${ }^{2}$; Fábio A Suinaga ${ }^{3}$; Rubens Ponijaleki ${ }^{4}$ \\ ${ }^{1}$ Embrapa Hortaliças/SPM, C. Postal 317, 89460-000 Canoinhas-SC; giovani.olegario@embrapa.br (*autor correspondente); ${ }^{2}$ Embrapa \\ Clima Temperado, C. Postal 403, 96001-970 Pelotas-RS; arione.pereira@embrapa.br; ${ }^{3}$ Embrapa Hortaliças, C. Postal 218, 70359-970 \\ Brasília-DF; fabio.suinaga@embrapa.br; ${ }^{4}$ Embrapa Produtos e Mercado, C. Postal 317, 89460-000 Canoinhas-SC; rubens.ponijaleki@ \\ embrapa.br
}

\section{RESUMO}

O objetivo do presente trabalho foi identificar a melhor época de dessecação das plantas para favorecer a qualidade de pele sem prejuízo do rendimento da cultivar de batata BRS Clara. O experimento foi realizado no campo experimental da Embrapa Produtos e Mercado, Canoinhas-SC. A cultivar Agata foi utilizada como testemunha. Os tratamentos utilizados foram quatro épocas de dessecação para cada cultivar (90, 95, 100 e 105 dias) após o plantio, no cultivo de primavera. O delineamento experimental foi em blocos casualizados com quatro repetições e parcelas com quatro fileiras de 10 plantas. Dez dias após as dessecações, foram colhidas as duas linhas centrais e os tubérculos avaliados para componentes de rendimento, aspereza e tonalidade de cor de pele. Os dados foram submetidos à análise de variância e de regressão polinomial. Verificou-se que, para a cultivar BRS Clara, a dessecação das plantas mais precocemente foi favorável, principalmente em relação à aspereza dos tubérculos. A data máxima para dessecação foi de 100 dias após o plantio, para a obtenção de tubérculos com boa qualidade de pele e sem maior redução do rendimento de tubérculos. Para a cultivar testemunha Agata, que apresentou melhor aparência de tubérculos, porém menor rendimento que 'BRS Clara', o retardamento da dessecação até próximo aos 100 dias do plantio também parece adequado, mas não devido à perda de qualidade da pele, e sim por ter atingido o rendimento máximo.

Palavras-chave: Solanun tuberosum, rendimento de tubérculos, aparência de tubérculos.

\begin{abstract}
Skin quality and yield of the potato cultivar BRS Clara

The objective of this study was to identify the best time of desiccation of plants to promote skin quality without detriment of potato cultivar BRS Clara. The experiment was carried out at Embrapa Produtos e Mercado, Canoinhas, Santa Catarina state, Brazil. 'Agata' was used as the control cultivar. The treatments were four desiccation times $(90,95,100$, and 105 days after planting), in spring season. The experimental design was randomized blocks with four replications. Each plot consisted of four rows of ten plants each. Ten days after desiccation of plants, the two internal rows of each plot were harvested and the tubers evaluated for yield component, skin roughness, and tone coloration of tuber skin. The data were submitted to analysis of variance and regression. For BRS Clara, a desiccation of the plants should be done earlier to avoid losses in quality of the skin, especially in relation to the roughness of the tubers. The maximum date for desiccation was 100 days after planting of tubers to obtain tubers with skin quality and no further reduction in yield of tubers. For the control cultivar Agata, that presented better tuber appearance than BRS Clara, but lower yield, delaying the desiccation date up to 100 days of planting also seems appropriate, but not due to loss of quality of the skin, but by having reached the maximum yield.
\end{abstract}

Keywords: Solanun tuberosum, tuber yield, tuber appearance.

(Recebido para publicação em 13 de julho de 2012; aceito em 4 de outubro de 2013) (Received on July 13, 2012; accepted on October 4, 2013)

\begin{abstract}
A obtenção de cultivares nacionais adaptadas às condições de cultivo das regiões produtoras brasileiras e resistentes às principais doenças é a alternativa mais viável para tornar a cultura mais produtiva e rentável para o produtor (Gadum et al., 2003). O grande desafio dos melhoristas de batata consiste em disponibilizar permanentemente cultivares que atendam às exigências dos consumidores, que cada vez mais priorizam produtos de qualidade (visuais e culinárias), dos produtores (maior rendimento aliado à precocidade) e das indústrias (qualidade industrial).

A cultivar de batata BRS Clara foi lançada no final de 2010 pela Embrapa,
\end{abstract}

possui ciclo vegetativo médio e destaca-se principalmente pela tolerância à requeima (Phytophthora infestans) e pelo grande rendimento de tubérculos comerciais; no entanto pode perder em qualidade da pele se não for colhida no momento correto e comercializada logo após a colheita (Pereira, 2010). Já a cultivar Agata, utilizada como testemunha neste trabalho, é a cultivar de pele amarela mais plantada no país, destaca-se pelo elevado rendimento e boa aparência de tubérculos (Pinto et al., 2010; Fernandes et al., 2011).

A aparência de tubérculos é um caráter muito importante em batata e é influenciado por diversos fatores, com destaque para a textura de pele e a tonalidade da cor dos tubérculos. Apesar da aparência da pele não ser um entrave na aceitação de uma cultivar por parte das indústrias, ela afeta efetivamente a aceitação do produto in natura pelos consumidores. Em se tratando de cultivares com pele amarela, os consumidores preferem tubérculos lisos e claros, por considerarem como batata recém colhida.

A aspereza de tubérculo bem como a tonalidade da cor são caracteres que sofrem influência ambiental, porém menor do que o caráter aparência geral de tubérculo que é um caractere mais complexo, do qual ambos os caracteres, 
tonalidade de cor e cor, são componentes (Silva et al., 2008a).

À medida que os tubérculos de batata se aproximam do final de seu desenvolvimento, a pele torna-se mais rugosa e escura, indicando muitas vezes a maturidade do tubérculo (Pereira \& Daniels, 2003). O rendimento de tubérculos é incrementado na medida em que o ciclo vegetativo das plantas avança e o amido é armazenado nos tubérculos. Os genótipos com ciclo maior tendem a ser mais produtivos (Silva et al., 2009).

Na cultura da batata, há a possibilidade de dessecação ou corte das ramas para finalizar o ciclo vegetativo das plantas quando os tubérculos já estão bem formados e a pele ainda está clara e lisa, como forma de obter um equilíbrio entre o maior rendimento e a melhor qualidade de pele.

Desta forma, este estudo objetivou identificar a melhor época de dessecação das plantas para favorecer a qualidade de pele sem prejuízo do rendimento para a cultivar de batata BRS Clara.

\section{MATERIAL E MÉTODOS}

O experimento foi realizado no campo experimental da Embrapa Produtos e Mercado, Canoinhas-SC (26 $10^{\prime} 38^{\prime \prime}$, $50^{\circ} 23^{\prime} 24^{\prime}$ 'O, altitude $839 \mathrm{~m}$ ) na primavera de 2011. O clima da região, segundo Köppen, é classificado como mesotérmico úmido, e o solo classifica-se como Cambissolo Háplico (Embrapa, 2006).

O delineamento experimental foi em blocos casualizados com quatro repetições e parcelas compostas por 40 plantas divididas em quatro linhas com 10 plantas, na forma de um fatorial $2 \times 4$, duas cultivares de batata (BRS Clara e a cultivar testemunha Agata) e quatro épocas de dessecação. As dessecações foram realizadas aos 90, 95, 100 e 105 dias após o plantio com o produto reglone $2 \mathrm{~L} \mathrm{ha}^{-1}$. Para ambas as cultivares foram utilizadas sementes do tipo II com quatro meses de armazenamento em câmara fria. Os tubérculos foram plantados espaçados em $0,80 \mathrm{~m}$ entre linhas e 0,40 $\mathrm{m}$ dentro da linha, no dia 17 de agosto de 2011. Como fertilizantes foram utilizadas $3 \mathrm{t} \mathrm{ha}^{-1}$ da fórmula comercial 4-14-08, recomendação feita com base em análise de solo. Os tratos culturais e fitossanitários seguiram as recomendações da região (Pereira \& Daniels, 2003). Não foi feita irrigação ou adubação de cobertura. Foi realizada aplicação de fungicidas a cada sete dias, intercalando os produtos oxicloreto de

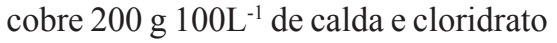
de propamocarbe + fluopicolide 1,5 L $\mathrm{ha}^{-1}$. Foi realizada aplicação de inseticidas a cada 15 dias com alfa-cipermetrina $0,5 \mathrm{~L} \mathrm{ha}^{-1}$.

Dez dias após cada dessecação (período necessário para fortalecer a pele), foram colhidas as duas linhas centrais e os tubérculos de cada parcela avaliados para os caracteres número de tubérculos comerciais por parcela (diâmetro transversal acima de $45 \mathrm{~mm}$ ); número de tubérculos não comerciais por parcela; número total de tubérculos por parcela; massa de tubérculos comerciais (g parcela ${ }^{-1}$ ); massa de tubérculos não comerciais (g parcela ${ }^{-1}$ ); massa total de tubérculos (g parcela $\left.{ }^{-1}\right)$; massa média de tubérculos ( $\mathrm{g}$ ), obtida pela divisão da massa total e o número total de tubérculos (g parcela $\left.{ }^{-1}\right)$. E, conforme Silva et al. (2008a), foram avaliados os caracteres aspereza de tubérculos, usando uma escala de notas $(1=$ liso a $5=$ áspero $)$; e tonalidade da coloração dos tubérculos, usando uma escala de notas ( $1=$ clara a $5=$ escura).

Os dados foram verificados quanto à distribuição normal dos resíduos por meio do teste de Lilliefors e submetidos à análise de variância e de regressão polinomial com utilização dos programas estatísticos Genes (Cruz, 2006) e SAS (SAS Learning Edition, 2002).

\section{RESULTADOS E DISCUSSÃO}

A característica tonalidade de cor de pele não apresentou distribuição normal dos resíduos e não foi considerada nas análises estatísticas. As datas de colheita foram significativamente diferentes para os caracteres número de tubérculos comerciais, massa de tubérculos comerciais, número total de tubérculos, massa total de tubérculos e aspereza da pele para a cultivar BRS Clara, e para massa de tubérculos comerciais, massa de tubérculos não comerciais e massa total de tubérculos para a cultivar Agata. Para os demais caracteres, não houve diferenças significativas, indicando que para estes os valores não foram alterados dos 90 aos 105 dias após o plantio (dados não apresentados).

Para ambas as cultivares, os coeficientes de variação ambiental (CV) foram baixos para os caracteres que apresentaram diferenças significativas, indicando boa precisão experimental. Estes valores estão abaixo dos encontrados em citações na literatura para componentes de rendimento de tubérculos em batata (Silva et al., 2006; Costa et al., 2007; Bisognin et al., 2008). O CV para a característica aspereza de tubérculo, foi semelhante ao reportado por Silva et al. (2008b) e Souza et al. (2008). A constatação de boa precisão experimental para os caracteres de rendimento de tubérculos é muito importante, por serem estes caracteres quantitativos e que normalmente sofrem grande influência ambiental (Silva et al., 2006).

A relação entre o coeficiente de variação genético e fenotípico $\mathrm{CVg} / \mathrm{CV}$ foi próximo ou superior à unidade para a maioria dos caracteres que apresentaram significância pela análise de variância para ambas as cultivares, indicando que a variação de ordem genética foi importante na manifestação da variação observada, em comparação com a ambiental. Silva et al. (2006) verificaram superioridade do valor do CV para caracteres relacionados ao rendimento de tubérculos de batata, enquanto Simon et al. (2009) obtiveram valores medianos a altos da relação $\mathrm{CVg} / \mathrm{CV}$, variando de 0,72 a 0,82 para o caráter produção de tubérculos por planta.

Pelos valores das médias (dados não apresentados), verifica-se que na média das diferentes datas de colheita a cultivar BRS Clara mostrou-se mais produtiva do que Agata, porém, com maior aspereza dos tubérculos. Assim, torna-se necessário identificar o melhor período para dessecação que permita equilíbrio entre rendimento e qualidade de pele.

A cultivar BRS Clara, que apresenta ciclo de desenvolvimento vegetativo um pouco mais longo do que a cultivar Agata, apresentou acréscimo do número de tubérculos (Figura 1D) e massa total de tubérculos (Figura 1C), bem como, 


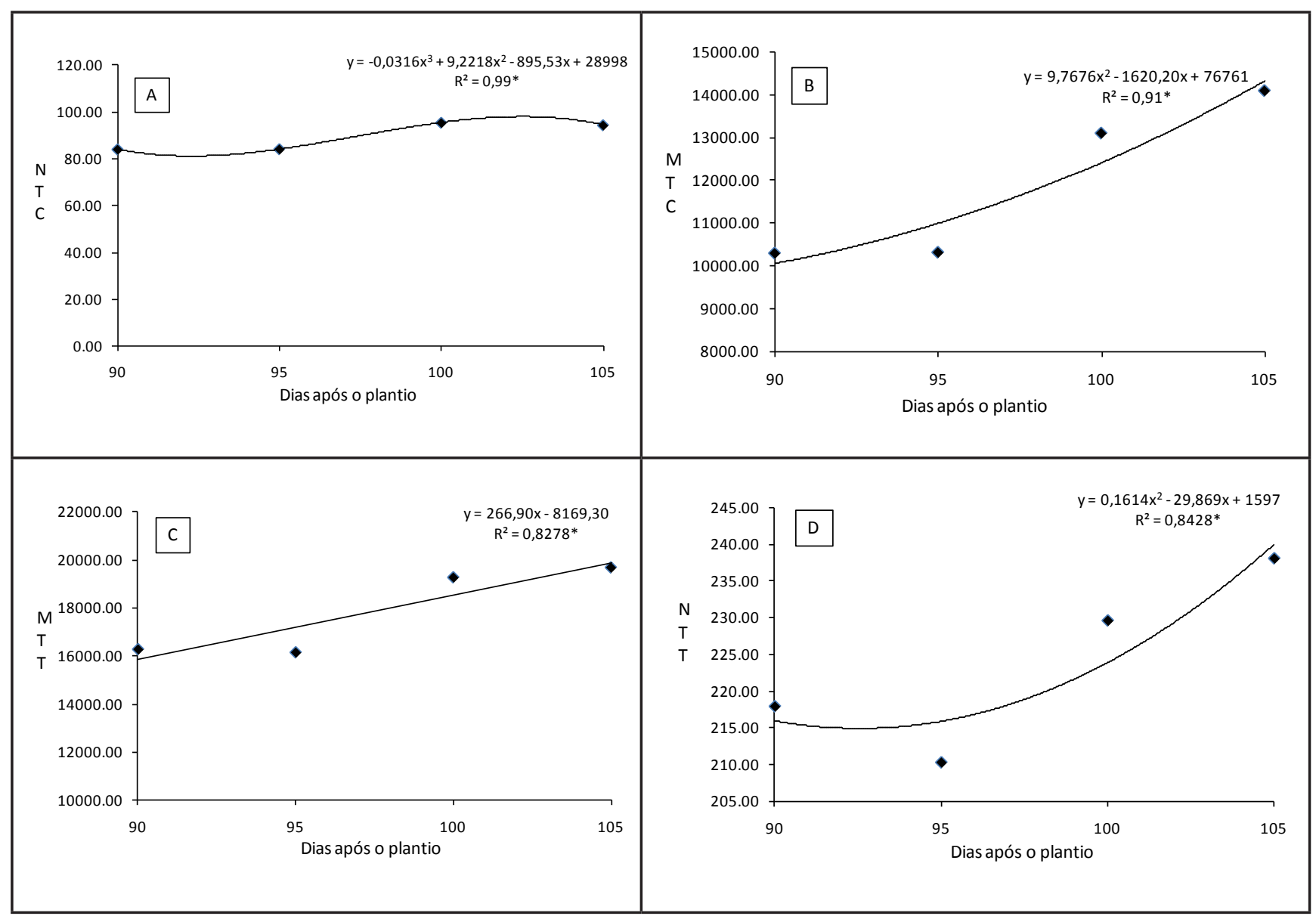

Figura 1. Relação do número de dias após o plantio com caracteres A: número de tubérculos comerciais (NTC), B: massa de tubérculos comerciais (MTC), C: massa total de tubérculos (MTT) e D: número total de tubérculos (NTT), para a cultivar de batata BRS Clara, *significativo a 5\% (relation of number of days after planting with A: number of marketable tubers (NTC), B: mass of marketable tubers (MTC), C: total mass of tubers (MTT), and D: total number of tubers (NTT) traits, for the potato cultivar BRS Clara; *significant at 5\%). Canoinhas, Embrapa Produtos e Mercado, 2011.

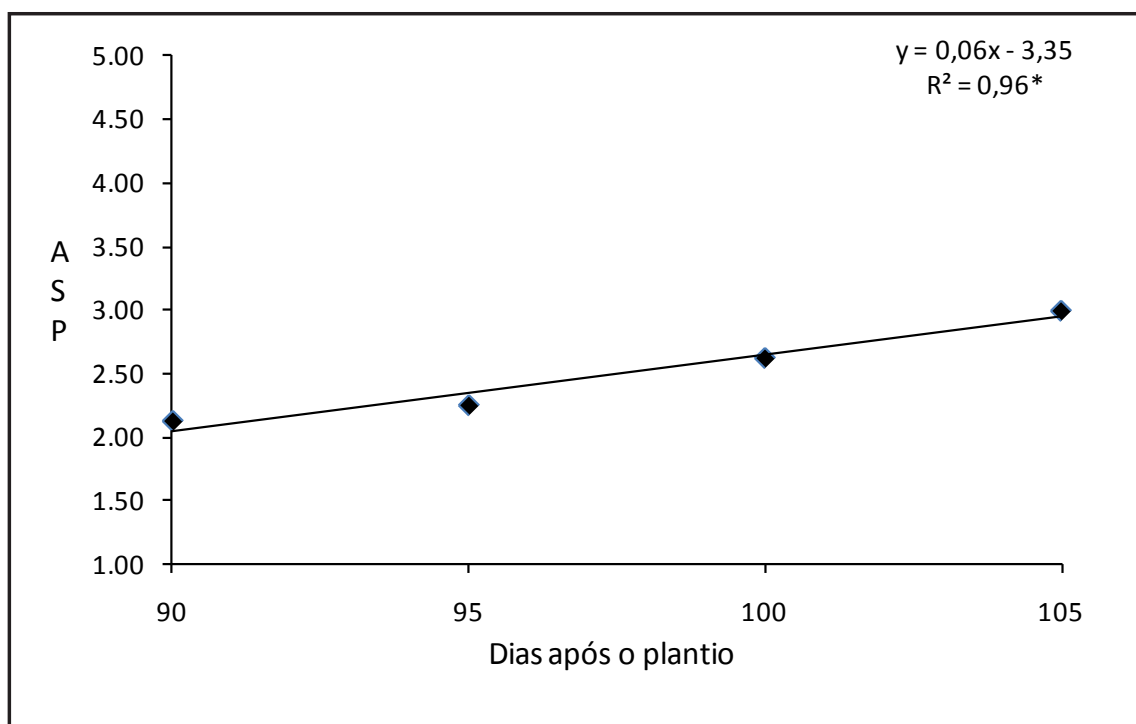

Figura 2. Relação do número de dias após o plantio com os caracteres aspereza de tubérculos (ASP), para a cultivar de batata BRS Clara, *significativo a 5\% (relation of number of days after planting with skin roughness (ASP), for the potato cultivar BRS Clara; *significant at 5\%). Canoinhas, Embrapa Produtos e Mercado, 2011. na massa de tubérculos comerciais até os 105 dias, porém, com acréscimo menor a partir dos 100 dias (Figura 1B). Em relação aos tubérculos classificados como comerciais, o acréscimo foi maior para a massa dos tubérculos (Figura 1B) do que em relação ao número de tubérculos (Figura 1A).

Para BRS Clara a aspereza dos tubérculos aumentou linearmente a partir dos 90 dias após o plantio (Figura 2).

A cultivar Agata, apesar de não ter apresentado aumento significativo do número de tubérculos comerciais em relação aos diferentes períodos de colheita, apresentou aumento significativo da massa de tubérculos comercias até os 105 dias (Figura 3A), apesar de a massa total de tubérculos não ter aumentado muito a partir dos 95 dias (Figura 3B). 


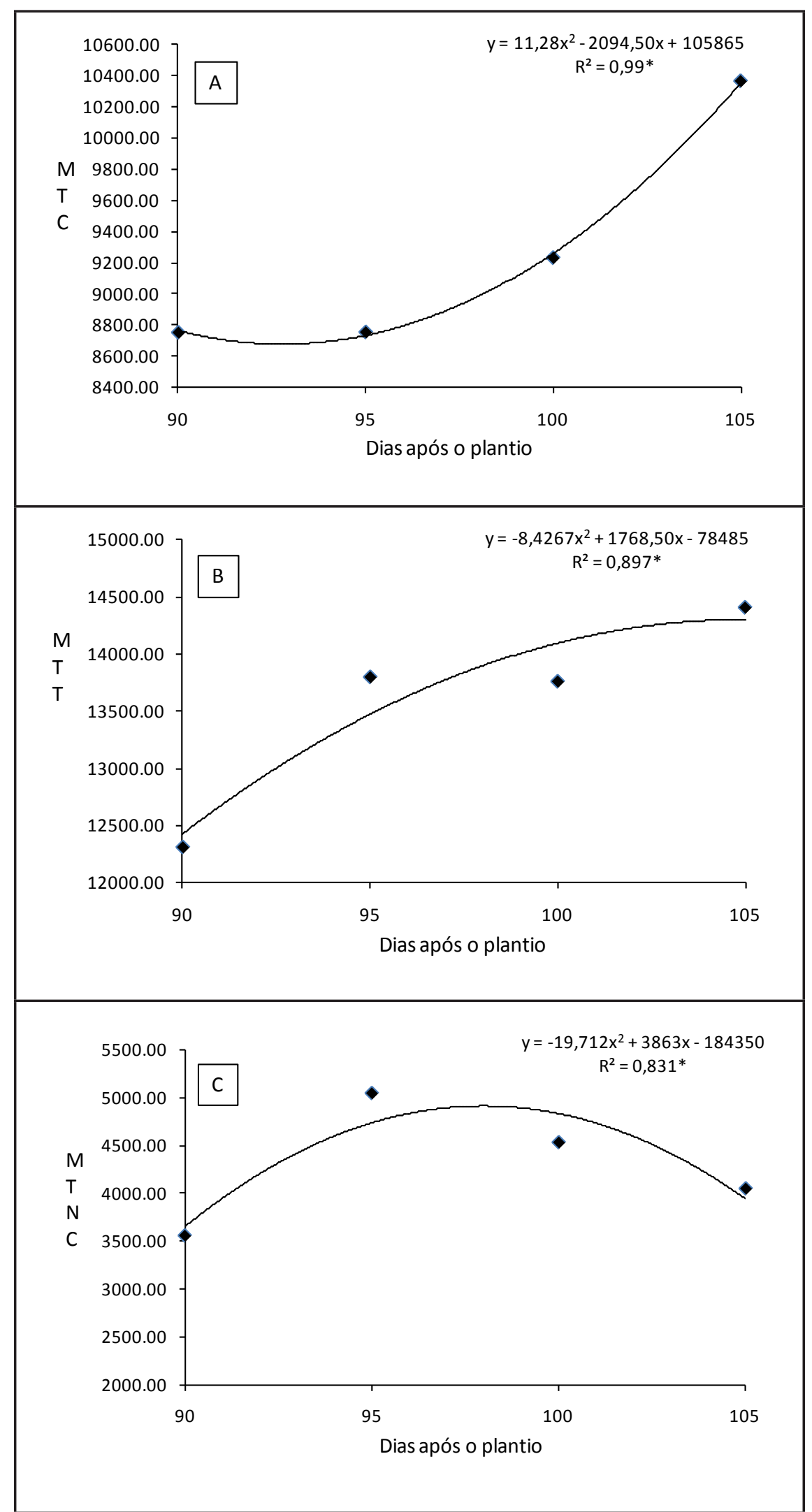

Figura 3. Relação do número de dias após o plantio com os caracteres A: massa de tubérculos comerciais (MTC), B: massa total de tubérculos (MTT) e C: massa de tubérculos não comerciais (MTNC), para a cultivar de batata Agata, *significativo a 5\% (relation of the number of days after planting with A: mass of marketable tubers (MTC), B: the total mass of tubers (MTT), and C: mass of non marketable tubers (MTNC) traits, for the potato cultivar Agata, *significant at 5\%). Canoinhas, Embrapa Produtos e Mercado, 2011.
A massa dos tubérculos não comerciais diminuiu com o passar do tempo (Figura 3C), devido ao aumento do tamanho dos tubérculos. Para esta cultivar, que se caracteriza pela precocidade e boa aparência de tubérculos, como verificado anteriormente, não houve acréscimo da aspereza dos tubérculos de 90 até 105 dias após o plantio.

Na prática, a determinação da melhor época para interromper o ciclo vegetativo, visando melhor equilíbrio entre rendimento de tubérculos e qualidade de pele, é realizada por meio da prospecção de tubérculos na lavoura. Segundo Andreu (2005), o caráter aspereza de pele, tratado naquele estudo como textura de pele, tende a ser estável na sua expressão mesmo em safras climatologicamente contrastantes. Da mesma forma, Silva et al. (2008a) citaram aspereza de pele e tonalidade da cor de tubérculos como caracteres de mediana herdabilidade no sentido amplo, ou seja, a variação de ordem genética se destaca para estes caracteres em relação à variação ambiental. Maris (1988) verificou altos valores de herdabilidade para aspereza de pele; apesar de ser um caráter influenciado por variações ambientais como a umidade e tipo de solo (Furumoto, 1997).

Os resultados deste trabalho, sugerem que para a cultivar BRS Clara este procedimento deve ocorrer o mais cedo possível para evitar perdas na qualidade de pele, principalmente em relação à aspereza. Neste estudo, a data máxima para dessecação foi 100 dias após o plantio, para a obtenção de tubérculos com qualidade de pele e sem maior redução do rendimento de tubérculos. Para a cultivar Agata, que apresentou melhor aparência de tubérculos que 'BRS Clara', porém menor rendimento, o retardamento da dessecação até próximo aos 100 dias do plantio também parece adequado, mas não devido à perda de qualidade da pele, e sim por ter atingido o rendimento máximo.

\section{AGRADECIMENTOS}

Ao CNPq pelo auxilio financeiro ao Programa de Melhoramento Genético de Batata da Embrapa. 


\section{REFERÊNCIAS}

ANDREU MA. 2005. Associação entre características agronômicas da batata nos plantios de primavera e outono no Rio Grande do Sul. Ciência e Agrotecnologia 29: 925-929.

BISOGNIN DA; MÜLLER DR; STRECK NA; ANDRIOLO JL; SAUSEN D. 2008. Desenvolvimento e rendimento de clones de batata na primavera e no outono. Pesquisa Agropecuária Brasileira 43: 699-705.

COSTA LC; BISOGNIN DA; ANDRIOLO JL; RITTER CEL; BANDINELLI MG. 2007. Identificação de clones de batata com potencial para mesa e adaptados para os cultivos de outono e primavera do Rio Grande do Sul. Ciência e Natura 29: 93-104.

CRUZ CD. 2006. Programa Genes: biometria: UFV. 382p.

EMPRESA BRASILEIRA DE PESQUISA AGROPECUÁRIA - EMBRAPA. 2006. Sistema Brasileiro de Classificação de Solos. 2ed. Rio de Janeiro. Embrapa Solos. 306p.

FERNANDES AM; SORATTO RP; EVANGELISTA RM; SILVA BL; SOUZASCHLICK GD de. 2011. Produtividade e esverdeamento pós-colheita de tubérculos de cultivares de batata produzidos na safra de inverno. Revista Ciência Agronômica 42: 502-508.
FUROMOTO O. 1997. Épocas de plantio. In: LOPES CA; BUSO JA. Cultivo da batata (Solanum tuberosum L.). Instruções técnicas Embrapa Hortaliças. Brasília: Embrapa Hortaliças p. 9-10.

GADUM J; PINTO CABP; RIOS MCD. 2003. Desempenho agronômico e reação de clones de batata (Solanum tuberosum L.) ao PVY. Ciência e Agrotecnologia 27: 1484-1492.

MARIS B. 1988. Correlations within and between characters between and within generations as a measure for the early generation selection in potato breeding. Euphytica 37: 205-209.

PEREIRA AS; DANIELS J. 2003. O Cultivo da batata na região sul do Brasil. Brasília: Embrapa Informação Tecnológica, p.105-123.

PEREIRA AS. 2010. BRS Clara, cultivar de batata para mercado fresco, com resistência a requeima. Folder. Pelotas: Embrapa Clima Temperado. $2 \mathrm{p}$.

PINTO CABP; TEIXEIRA AL; NEDER DG; ARAÚJO RR; SOARES ARO; RIBEIRO GHMR; LEPRE AL. 2010. Potencial de clones elite de batata como novas cultivares para Minas Gerais. Horticultura Brasileira 28: 399-405.

SAS LEARNING EDITION - Getting Started with the SAS Learning Edition. 2002. Care, North Carolina: SAS Institute Inc. CDRoom. SILVA GO; SOUZA VQ; PEREIRA AS,
CARVALHO FIF; FRITSCHE-NETO R. 2006. Early generation selection for tuber appearance affects potato yield components. Crop Breeding and Applied Biotechnology 6: 73-78.

SILVA GO; PEREIRA AS; SOUZA VQ; CARVALHO FIF; VIEIRA EA. 2008a. Qualidade de pele de famílias clonais de batata. Bragantia 67: 633-638.

SILVA GO; PEREIRA AS; SOUZA VQ; CARVALHO FIF; VIEIRA EA. 2008b. Capacidade de combinação multivariada para caracteres de tubérculo em gerações iniciais de seleção em batata. Ciência Rural 38: 321-325.

SILVAFL; PINTO CABP; ALVES JD; BENITES FRG; ANDRADE CM; RODRIGUES GB; LEPRE AL; BHERING LP. 2009. Caracterização morfofisiológica de clones precoces e tardios de batata visando à adaptação a condições tropicais. Bragantia 68: 295-302.

SIMON GA; PINTO CABP; LAMBERT ES; ANDREU MA. 2009. Seleção de clones de batata resistentes à pinta preta e tolerantes ao calor. Ceres 56: 31-37.

SOUZA VQ; PEREIRA AS; SILVA GO; FRITSCHE-NETO R; CASTRO CM. 2008. Avaliação de genótipos de batata selecionados para resistência a insetos-praga. Boletim de pesquisa e Desenvolvimento, 65. Pelotas: Embrapa Clima Temperado. 27p. 